\title{
A case study evaluation of an intervention aiming to strengthen the midwifery professional role in Morocco: anticipated barriers to reaching
}

\section{outcomes}

\author{
This article was published in the following Dove Press journal: \\ Journal of Multidisciplinary Healthcare \\ 21 September 2015 \\ Number of times this article has been viewed
}

\author{
Sabina Abou Malham ${ }^{1,2}$ \\ Marie Hatem ${ }^{1,2}$ \\ Nicole Leduc ${ }^{1,3}$ \\ 'IRSPUM, Université de Montréal, \\ Montréal, QC, ${ }^{2}$ Department of Social \\ Preventive Medicine, Université de \\ Montréal, Montréal, QC, ${ }^{3}$ Department \\ of Health Administration, School of \\ Public Health, Université de Montréal, \\ Montréal, QC, Canada
}

Background: In order to reduce the high maternal mortality ratio, Morocco is strongly committed to strengthen its midwifery professional role. This study aimed to identify barriers that could potentially hinder an action plan to strengthen the midwifery professional role from achieving desired outcomes. We used a conceptual framework, which is derived from HatemAsmar's (1997) framework on the interaction of educational, professional, and sociocultural systems in which a professional role evolves and from Damschroder et al's (2009) framework for the implementation analysis.

Methods: This paper builds on a qualitative case study on the factors affecting the action plan's implementation process that also revealed rich data about anticipated barriers to reaching outcomes. Data were collected through training sessions, field observations, documents, focus groups $(n=20)$, and semistructured interviews $(n=11)$ with stakeholders pertaining to the three systems under study. Content analysis was used to identify themes related to barriers.

Results: Seven barriers that may compromise the achievement of desired results were found. They relate to the legal framework, social representations, and media support in the sociocultural system and the practice environment, networks and communication mechanisms, and characteristics related to the role and the readiness in the professional system.

Conclusion: Disregarding sociocultural and professional system level, barriers may impede efforts to strengthen the midwife's role and to provide qualified midwives who can improve the quality of maternal care. Making changes in the educational system cannot be thought of as an isolated process. Its success is closely tied with multiple contextual factors pertaining to the two other systems. Activities recommended to address these barriers may have great potential to build a competent midwifery workforce that contributes to positive maternal and neonatal health outcomes.

Keywords: evaluation, outcomes, barriers, professional role, midwife, maternal mortality

\section{Background}

A global call to action against high maternal mortality ratios (MMRs) in developing countries has renewed the focus on the need for skilled care and has put midwives in pole position to improve the quality of care, as well as maternal, infant, and neonatal health outcomes. ${ }^{1-3}$ As such, interventions aiming to strengthen the midwifery workforce have become the key for achieving the millennium development goals 4 and 5 - to reduce child mortality and to improve maternal health. ${ }^{4}$ Hence, the challenges that may lie ahead with regards to implementing and reaching outcomes of such interventions should not be overlooked. The influence of contexts and the challenging conditions
Correspondence: Sabina Abou Malham Department of Social and Preventive Medicine, School of Public Health, Université de Montréal, PO Box 6128, Centre-ville Station, Montréal, Québec, Canada, H3C 3J7 $\mathrm{Tel}+$ I 5 I4 3436 I I I(44023)

Fax +I $5 \mid 43435645$

Email sabina.abou.malham@umontreal.ca/ sabina_aboumalham@hotmail.com 
of these contexts can be distinguished at two levels: 1) in implementing the intervention according to the design and 2) in producing the desired results. ${ }^{5,6}$ Several evaluative studies in various fields such as social, education, and health care have studied contextual conditions under which interventions reach their intended outcomes. ${ }^{7-9}$ According to Stetler et al, ${ }^{6}$ monitoring these conditions may help identify the factors that are blocking progress toward desired outcomes. Indeed, it has been postulated that analyzing contextual influences may help us understand the factors that contribute to reaching an intervention's full potential while reinforcing progress toward its goals..$^{5,10}$ Johnson et $\mathrm{al}^{10}$ also point to the importance of "the program-environment fit" for attaining educational and preventive program objectives. In summary, interventions are more likely to be successful if optimal contextual conditions are provided. Therefore, monitoring these conditions should be an integral part of the implementation process and of outcome evaluations of interventions, specifically those aiming to strengthen the midwifery workforce.

To support the achievement of MDG 5, Morocco has been experimenting, since 2008, with setting up a "strengthening midwifery" action plan proposed by a consultant (Hatem, unpublished data, 2008). It was implemented as part of a national health strategy's core action, which focuses on strengthening human resources competencies - including midwifery - as a key government strategy to decrease the high MMR (227 per 100,000 live births as estimated in 2003). ${ }^{11}$ After 18 months of implementation, an evaluation study revealed a noticeable failure in the execution of the action plan: the activities implemented emphasized the delivery of educational activities. ${ }^{12}$ Consequently, only three out of the nine action plan objectives were considered and partially implemented by the training division affiliated with the Ministry of Health (MOH) between June 2009 and November 2010, reflecting a failed implementation of other recommended components (eg, legal, social, and professional activities). In addition to identifying contextual influences on the implementation's progress, the evaluation study revealed context-related information that may adversely prevent the intervention, as it has been implemented, from attaining intended outcomes. The need to consider anticipated contextual barriers - in order to optimize the intervention's benefits - was constantly brought up by the participants during field research. In summary, our evaluation yielded two types of results: 1) the first concerns the contextual factors affecting the implementation process of the action plan; and 2) the second addresses the potential barriers to achieving the intended outcomes while implementing only the educational component of the action plan. In the present paper, we focus only on the latter.

Our objective is twofold: 1) to identify the contextual factors that were perceived as hindering the partially implemented action plan (educational activities) from achieving the desired outcomes; and 2) to identify the recommendations that could increase the effectiveness of the action plan setup in Morocco.

\section{Context of the intervention: history of development and implementation of a complex intervention aiming to strengthen the midwifery professional role in Morocco}

In Morocco, a global action plan was developed in 2008 and was implemented by 2009 , following diagnostic and validation phases conducted in February 2008. It was designed by a consultant based on a conceptual framework stipulating that three systems (sociocultural, educational, and professional) are crucial and should be targeted by an intervention aiming to change a professional role. ${ }^{13}$ Consequently, the conceptual foundations for designing the intervention led to an operational action plan comprising nine objectives and relevant activities. In fact, the action plan took a wider approach and was aiming at multiple changes rather than only educational changes (eg, curriculum review and implementation of competency-based education [CBE], continuing education program) as initially requested by the human resources department of the $\mathrm{MOH}$. The additional changes suggested to improve the midwifery role, following the diagnostic analysis, included changes to the midwifery profile and care provision, the midwifery legislation, and the professional midwifery association and community recognition, as well as changes to the organization of human resources in the Moroccan health system. In summary, the action plan was intended to adopt a systemic approach to strengthen the midwifery role. The intended outcomes of the action plan (if fully implemented) were to provide a qualified midwifery workforce that would contribute to the improvement of the quality of health services and, ultimately, to the reduction of maternal and neonatal mortality.

Following 18 months of implementation, the analysis revealed a significant divergence between the action plan's intended activities and those put in place. The failure of the implementation process was mainly due to the result of the interaction between a variety of factors pertaining to the context (the three systems in which the action plan was 
introduced) and the characteristics of the intervention itself. The results of the implementation process evaluation are presented in a separate paper.

\section{Conceptual framework}

We developed an evaluative conceptual framework ${ }^{14}$ that was built based on Hatem-Asmar et al's ${ }^{13}$ conceptual model on changing a health professional's role and based on Damschroder et al's ${ }^{16}$ meta-theoretical framework for implementation analysis. Our framework was initially elaborated to gain understanding of the implementation process of an intervention aiming to strengthen a health professional's role. As such, Hatem-Asmar's model was used to delineate the context through which an intervention needed to be disseminated across the dimensions (values, actors, methods, and targets) of the three interacting systems (sociocultural, professional, and educational) in order to change a health professional's role. On the other hand, the consolidated framework for implementation research (CFIR) ${ }^{15}$ provides a taxonomy of constructs that are likely to influence the implementation of complex interventions organized into five major domains: 1) intervention characteristics, 2) outer setting, 3) inner setting, 4) characteristics of individuals, and 5) process of implementation. It was used as an analytical tool to frame the observed barriers and facilitators through its "menu of constructs", within the four dimensions of each of the three systems and the intervention. This was done by inductively mapping thematic codes during data analysis onto the constructs level of the CFIR domains. Constructs of two domains (inner and outer settings) were applied to the dimensions of the three interacting systems and were not classified under inner and outer settings domains; as in our case, there is no single set of inner/outer settings due to the complex nature of the interrelated systems under study.

As has been acknowledged, conceptual frameworks may evolve according to new research findings from empirical fieldwork. ${ }^{16}$ This applied to our case, as emerging results regarding the factors that might also affect the intervention's effectiveness (anticipated barriers to reaching outcomes) contributed to further the development of our initial framework. Therefore, in the present paper, we present a modified version of our conceptual framework, enriched with a second type of evaluation results related to outcomes (the highlighted yellow area) found in this study (Figure 1). Thus, the final version of our framework proposes three systems (sociocultural, educational, and professional) interacting with the intervention

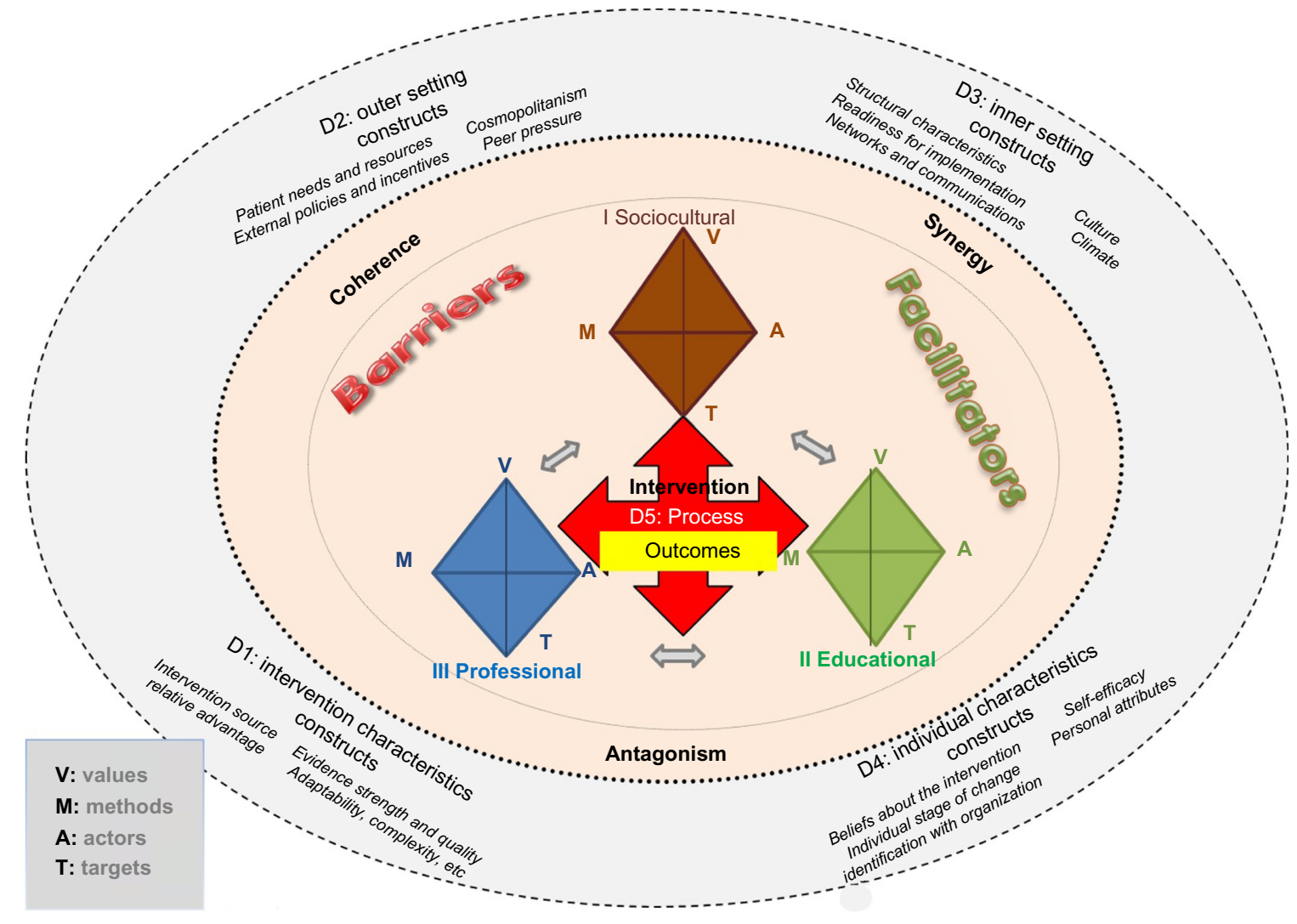

Figure I Advanced version of the conceptual framework to evaluate the implementation of a complex intervention aiming to change a health professional's role. 
within which the successful or failed implementation process and the intervention performance or outcomes are interpreted. It considers a set of dimensions in each system arguing that barriers or facilitators identified according to the CFIR's "menu of constructs" could be located in the interaction of these dimensions with the intervention. These dimensions are examined through the CFIR lens in order to understand: 1) how the implementation process occurred and what factors influenced it; and 2) how this might influence reaching outcomes.

\section{Methods}

\section{Design}

The present paper builds on a qualitative case study that was conducted to capture data on the influence of the context on the intervention's implementation, which also revealed rich data about the anticipated barriers to reaching outcomes. This approach aims to understand the case (the midwifery profession undergoing the implementation process of an action plan) in depth within its real-life context ${ }^{17}$ and to examine the views of a range of different stakeholder groups pertaining to the three systems under study. In this study, we focus only on the barriers to reaching outcomes.

\section{Defining the research steps: reorienting the focus of research according to the real context}

The focus of our main case study was primarily on eliciting barriers and facilitators encountered with respect to implementing the intervention. However, as the study evolved, research data provided valuable insights related to contextual factors that might impede the success of the partially implemented action plan and were beyond the scope of our initial research. Given the richness of data, well worth being taken into consideration, we decided 1) to redraw the boundaries in light of emerging results and 2) to refine the focus of our research as broadly as possible to themes related to the anticipated barriers to reaching outcomes that were present in almost all data. Leaving the scope sufficiently open to unintended, context-generated information ${ }^{18}$ and "allowing research findings to emerge from the frequent themes inherent in raw data, without imposing any restraints by structured methodologies" has been recognized as one advantage of the inductive qualitative approach. ${ }^{19}$ Taking into account the perceptions of front-line informants, is crucial to better inform decision makers about the potential barriers to attain the short, intermediate, and long term outcomes targeted by the action plan. Our consideration of these results is consolidated by many authors who stipulate that if an intervention is only partially implemented, it would not be surprising to find no effects or to expect the intervention's effectiveness to be diminished. ${ }^{9,20,21}$

Through this article, we are clarifying the contextual factors that represent challenges for attaining the intended outcomes of the partially implemented action plan and the factors that are essential for its effectiveness. Identifying these factors may result in either redesigning or adapting the intervention (readjusting the other components of the intervention) or, later, considering its full adoption. Ignoring the factors that might interact with the implemented intervention jeopardizes the attainment of positive outcomes. ${ }^{5,22}$ It is essential to understand why, in our case, one component of the action plan alone might not work in terms of providing a qualified midwifery workforce that contributes to positive maternal and neonatal health outcomes. In our case study, the educational activities are considered as the intervention interacting with the context that influences the outcomes that are initially presumed to be attained by the action plan (type III analysis: typology of implementation analysis according to Champagne et al. ${ }^{5}$ )

\section{Setting, participants, and sampling}

Two regions (Rabat and Tétouan), which were participating in the implementation process and were concerned by the ongoing activities, were selected for the study. The study was carried out during June and July 2010 through intensive immersion into the field, $\sim 18$ months after starting the implementation phase of the action plan. Using purposeful sampling, we selected stakeholders pertaining to the three systems and to the intervention under investigation seeking to achieve maximum variation on numerous dimensions such as different positions and disciplines (medical administrative officers, academic directors, midwifery educators and students, nurses, midwives, obstetricians, physicians, medical directors, senior nurse managers, and midwife managers). The aim was to capture a broad range of perspectives of key informants ${ }^{19}$ who were either involved in the implementation process or concerned by the overall implementation of the action plan. We relied on the potential of each key informant for yielding insight into and understanding of the implementation.

The final sample consisted of 107 informants (106 key Moroccan informants and one international consultant) drawn from health care services (two health care centers, two birthing homes, and two maternity hospitals), educational institutes (two Instituts de Formation aux Carrières de Santé-IFCS), the Moroccan Midwives Association, departments affiliated 
to the Ministry of Public Health (Directorate of population, training division, and two regional delegations), and the United Nations Population Fund (UNFPA) office, in the two regions. Despite the fact that two educational institutes were approached to take part in the study, we were able to capture a diversity of meaningful data across ten different educational institutes as midwifery educators involved in the ongoing activities came from many regions across Morocco. Although not specifically involved in the implementation, consideration was given to women's views on some particular aspects of receiving midwifery services (eg, the benefits and difficulties of implementing an intervention to strengthen the midwifery role). Table 1 presents characteristics of the participants.

The study was approved by the Research Ethics Committee of the Université de Montréal, Québec, and the $\mathrm{MOH}$ in Morocco. Written consent forms were obtained from all participants.

\section{Data collection}

Data collection consisted of in-person interviews $(n=11)$, focus groups (FGs) $(n=20)$, documents $(n=16)$ related to the project (eg, technical reports on the different sessions implemented, funder letters, correspondence between different parties concerning the project), and field notes based on direct field observations (FOs) and natural site visits (educational institutes and clinical settings) $(n=13)$. Repeated observations took place at different times during the educational activity sessions of the action plan (Tétouan session to validate the midwifery program, Rabat train-the-trainers [TTT] session) over an 30-hour period of observation. We used a semistructured interview guide based on our conceptual framework. Participants were asked to describe their perceptions of the action plan, the implemented activities (educational), and factors they perceived as influencing the implementation, and their experiences with the process. Interviews varied in length from 50 to 90 minutes. We made sure to compose homogeneous groups to avoid mixing informants belonging to different organizational hierarchy in order to allow liberal sharing of opinions. Of the 31 interviews, eight were not audiotaped in one region, and detailed notes had to be taken manually by the first author (SAM) using abbreviations due to the refusal of participants to be recorded. Interviews were mostly conducted in French (only women were interviewed in Arabic).

\section{Data analysis}

The analysis was conducted combining deductive and inductive approaches using the methods suggested by Miles and Huberman. ${ }^{16}$ In the first stage of the analysis, we applied a deductive approach building on the four dimensions (values, methods, actors, and targets) of the proposed

Table I Characteristics of the participants in the study

\begin{tabular}{|c|c|c|c|c|c|c|}
\hline \multirow[t]{2}{*}{ Job title/current position } & \multirow{2}{*}{$\begin{array}{l}\text { Participants } \\
\text { (N) }\end{array}$} & \multicolumn{2}{|l|}{ Sex } & \multirow{2}{*}{$\begin{array}{l}\text { Work experience } \\
\text { Mean (range)* }\end{array}$} & \multirow{2}{*}{$\begin{array}{l}\text { Rural setting } \\
\text { experience yes }\end{array}$} & \multirow{2}{*}{$\begin{array}{l}\text { Urban setting } \\
\text { experience yes }\end{array}$} \\
\hline & & $\begin{array}{l}\text { Male } \\
\text { n (\%) }\end{array}$ & $\begin{array}{l}\text { Female } \\
\text { n (\%) }\end{array}$ & & & \\
\hline Midwives practitioners & 17 & 0 & 17 & $11.29(1-25)$ & 16 & 17 \\
\hline Nurses & 5 & I & 4 & $20(9-28)$ & 2 & 5 \\
\hline Obstetricians & 6 & 5 & I & $7.66(1-16)$ & 3 & 6 \\
\hline Physicians & 2 & 1 & I & 24.5 & $\mathrm{I}$ & 2 \\
\hline Medical directors & 2 & 2 & 0 & 23.5 & I & 2 \\
\hline Senior nurse managers & 2 & 1 & I & 16 & 2 & 2 \\
\hline Midwife managers & 2 & 0 & 2 & 26.5 & 2 & 2 \\
\hline Midwifery representatives & 2 & 0 & 2 & 33.5 & I & 2 \\
\hline Midwifery educators & 29 & 0 & 29 & $15.25(6-32)$ & 24 & 29 \\
\hline Midwifery students & 15 & 0 & 15 & N/A & N/A & N/A \\
\hline Academic directors & 2 & 1 & I & 32.5 & I & 2 \\
\hline Academic management staff & 4 & 3 & I & $28.5(24-37)$ & 4 & 4 \\
\hline Medical administrative officers & 7 & 6 & I & $19.85(15-29)$ & 7 & 7 \\
\hline Administrative nurse managers & 2 & 0 & 2 & 23.5 & 1 & 2 \\
\hline Health programmer & I & I & 0 & $16 *$ & I & I \\
\hline Women & 8 & 0 & 8 & N/A & $\mathrm{N} / \mathrm{A}$ & $\mathrm{N} / \mathrm{A}$ \\
\hline Consultant & I & 0 & I & $29 *$ & N/A & N/A \\
\hline Participants, n(\%) & 107 & 21 (19.63\%) & $86(80.37 \%)$ & N/A & 66 (79.52\%) & $100 \%$ \\
\hline
\end{tabular}

Note: *Indicates data is expressed in years.

Abbreviation: N/A, not applicable. 
framework. Then, an inductive thematic analysis allowed themes to emerge. A pre-established list of codes, developed according to the afore-mentioned dimensions, guided the initial coding. First, texts were read to gain familiarity with content. Second, data were broken into first-level codes and classified under four mega codes (values, methods, actors, and targets) within each data set. Third, they were compared within and across cases, and similar ones were combined. Fourth, they were aggregated into themes and were assigned to the "barriers" category (the "facilitators" category did not yield any results). The emerging themes were identified and mapped on to the CFIR constructs (when applicable), which helped to identify the subcodes. Coding rules were specified in a qualitative codebook (Table 2).

Data analysis was undertaken by the first author (SAM). Trustworthiness was ensured through a variety of methods: regular meetings were held with the co-authors $(\mathrm{MH}$ and NL) during the coding process to discuss themes and related codes within each system and to reach consensus on final codes; a selection of transcripts was also reviewed by an independent researcher to help maximize the validity of the findings. Data sources were triangulated by cross-checking the different point of views of actors belonging to the three systems and by checking the views expressed against written documents. This was used to reduce bias and to strengthen confidence in the conclusions drawn. ${ }^{19}$

\section{Results}

Seven barriers distributed over two dimensions of each of the sociocultural (values and methods) and professional (methods and actors) systems were reported (Table 3). Among the seven themes, only three themes resonate with three constructs of the CFIR: one pertaining to the outer setting domain ( 1 - external policies and incentives) and other two to the inner setting domain $(2$ - networks and communication; 3 - readiness for implementation/available resources). Furthermore, as interviewees provided their perspectives on activities that must be put in place to address barriers, we decided to group both under the same themes.

\section{The sociocultural system \\ Values}

External policies and incentives (regulations): Archaic legal and regulatory framework

The midwifery outdated legal and regulatory framework was perceived as a major barrier to the success of the educational activities implemented. The impact of such outdated legislation and the lack of a clear and formalized statute governing the midwifery profession is that it prevents midwives from fulfilling any expanded role or assuming additional responsibilities. It was described as impeding the current educational activities put in place from reaching their objectives: even if midwifery training becomes "competencybased", it will not be sufficient to allow a midwife to apply what she has learned. One medical administrative officer reported that "without changing the law, midwives can't perform the role for which they are being educated and all is doomed to failure" [MedicalAdministrativeOfficer1]. Another central concern was the current legislation that jointly regulates midwives, nurses, and other health professions. The absence of midwifery-specific legislation, which would entail its own practice standards, hinders the intervention from attaining its objectives. It was reported that current legislation impacts the practice of midwifery according to the competency-based approach: "midwives cannot work without legal protection aligned with the new competencies" [FG_MedicalAdministrativeOfficers2].

According to some interviewees, undertaking a review of legislation is required, as stated below:

The training program on its own will not ensure reaching the desired strengthening of the midwifery profession; there should be other issues taken into consideration and other supporting measures such as legislative measures.

[FG_MidwiferyEducators1]

Social representations: poor image of the midwife and lack of public awareness of her role

Negative perceptions and misunderstanding of the midwife's image prevail at the community level. Midwives are often perceived as physicians' assistants and as subservient to obstetricians [FG_MedicalAdministrativeOfficers2]. They are confused with traditional midwives, and sometimes people are unable to differentiate them from nurses. Midwives have become devalued by the wider society; their role is not understood and is restricted to being "a birth attendant practicing only the art of delivering babies" [FG_MidwiferyStudents1]. They are also viewed as not being humane "slapping women and yelling at them" [AdministrativeNurseManager1]. The lack of visibility of midwives was reported as a major problem in Morocco. Moreover, it was stated that in rural areas, the presence of the traditional midwife (Kabla) among the community means that the midwife has to compete with this traditional health personnel, who has more power within the community despite her unsafe practices [FO_TTT_N9]. Due to the negative representations of midwives, many 
Table 2 Qualitative codebook

\begin{tabular}{|c|c|c|}
\hline Damschroder & Definition & Rules for identifying and mapping themes \\
\hline \multicolumn{3}{|c|}{ CFIR's constructs (Damschroder et $\mathrm{al}^{15}$ ) } \\
\hline Implementation process & $\begin{array}{l}\text { How well the implementation is carried out } \\
\text { according to plan, how well executing was done } \\
\text { according to plan }\end{array}$ & $\begin{array}{l}\text { Statements regarding the conceptual dimensions of the } \\
\text { construct executing including the: } \\
\text { - degree of fidelity of implementation to planned courses of action } \\
\text { - intensity (quality) of implementation } \\
\text { - timeliness of task completion } \\
\text { - degree of engagement of key actors in the implementation } \\
\text { process }\end{array}$ \\
\hline Intervention's effectiveness & Refers to the intervention's performance & $\begin{array}{l}\text { Statements regarding how the intervention might reach the } \\
\text { outcomes as initially intended }\end{array}$ \\
\hline External policy and incentives & $\begin{array}{l}\text { A broad construct that includes external strategies } \\
\text { to spread interventions including: local, state, or } \\
\text { national policies, regulations, external mandates, } \\
\text { guidelines and recommendations that influenced } \\
\text { the decision to implement the intervention. }\end{array}$ & Codes relating to one or several elements of the definition \\
\hline $\begin{array}{l}\text { Networks and } \\
\text { communications }\end{array}$ & $\begin{array}{l}\text { The nature and quality of social networks and of } \\
\text { formal and informal communications within an } \\
\text { organization. Refer to general communication and } \\
\text { relationships in the organization }\end{array}$ & Codes relating to one or several elements of the definition \\
\hline $\begin{array}{l}\text { Readiness for implementation: } \\
\text { Available resources }\end{array}$ & $\begin{array}{l}\text { Tangible indicators of organizational commitment } \\
\text { to its decision to implement an intervention: } \\
\text { - Level of resources dedicated for } \\
\text { implementation including money, } \\
\text { training, education, physical space, equipment, } \\
\text { and information technology }\end{array}$ & $\begin{array}{l}\text { Codes relating to one or several elements of the three sub- } \\
\text { constructs of the definition }\end{array}$ \\
\hline \multicolumn{3}{|c|}{ Other concepts not covered by the CFIR menu of constructs } \\
\hline Social representations & $\begin{array}{l}\text { Representations (social values, ideas, beliefs) of } \\
\text { midwives, their role held within the general social } \\
\text { and cultural environment }\end{array}$ & $\begin{array}{l}\text { Statements regarding the nature of representations held } \\
\text { with the social and cultural environment regarding midwives, } \\
\text { their role which may play a role in facilitating/hindering the } \\
\text { attainment of the intervention's outcomes }\end{array}$ \\
\hline Media support & The nature of support provided by the media & $\begin{array}{l}\text { Statements regarding how the media is supporting the } \\
\text { Moroccan midwives which may play a role in facilitating/ } \\
\text { hindering the attainment of the intervention's outcomes }\end{array}$ \\
\hline Practice environment & $\begin{array}{l}\text { The environment in which care is delivered and } \\
\text { the characteristics of the work environment that } \\
\text { facilitate or constrain the professional practice }\end{array}$ & $\begin{array}{l}\text { Statements regarding how the work environment and } \\
\text { conditions may play a role in the attainment of the } \\
\text { intervention's outcomes }\end{array}$ \\
\hline
\end{tabular}

Notes: The constructs of the CFIR that applied to our results are the only ones described in this table. Adapted from Damschroder LJ, Aron DC, Keith RE, Kirsh SR, Alexander JA, Lowery JC. Fostering implementation of health services research findings into practice: a consolidated framework for advancing implementation science. Implement Sci. 2009;4:50. Creative Commons license and disclaimer available from: http://creativecommons.org/licenses/by/4.0/legalcode..$^{15}$

Abbreviation: CFIR, consolidated framework for implementation research.

interviewees emphasized the need to consider acting to fight the negative image of midwifery, to raise public awareness and the acceptability of midwifery services [FO_TTT_N7; FG_MidwiferyEducators1]. This was reported as "a primary objective for the profession $[\ldots]$ that we should concentrate on, apart from focusing on educational activities" [FO_TTT_ $\mathrm{N} 8$ ], in order to strengthen the midwife's role.

\section{Methods}

Media support: disadvantageous media coverage for midwives and women

Midwives reported that the media convey wrongful messages about them and that the focus is always on obstetric nurses and physicians rather than on midwives [NurseManager2]. Aspects of the media's ignorance were reported, such as having traditional midwives speak about maternal health care when this topic comes up in the media, instead of inviting midwives. The lack of media support was illustrated by many midwives, such as "not disseminating aspects of care provided by midwives in order to enhance midwives' visibility in the society and to build trust between midwives and members of the community" [FG_MidwiferyEducators2], and also the media focuses on maternity hospitals rather than on midwives' role in birthing homes. The media does not proceed to community mobilization by improving access to information about the importance of prenatal care and of being attended to by a skilled midwife: 


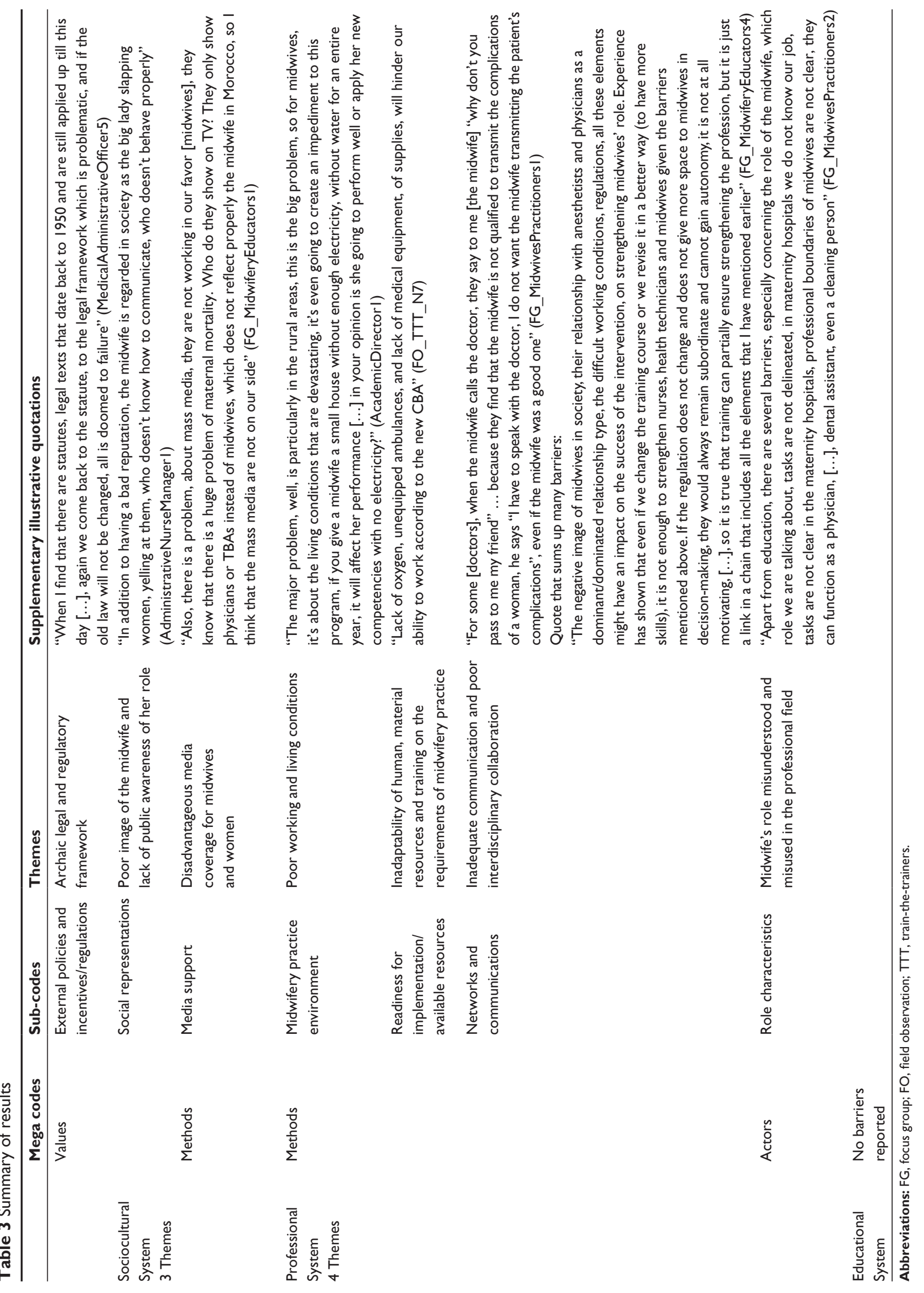


There is no advertising for midwives, they do not broadcast information about midwives, their role, and there are no educational activities through the media on the importance of the follow-up during pregnancy. [FG_MidwivesPractitioners2]

\section{The educational system}

Barriers were mainly related to the contextual influence on the implementation process.

\section{The professional system Methods \\ Midwifery practice environment: poor working and living conditions}

Informants believed that despite the educational activities being implemented, inadequate working conditions, such as low salaries for health professionals and for midwives, in particular, excessive workload and inadequate remuneration, are factors that hinder the attainment of the desired results, which is to improve the quality of maternity health care provided by a competent midwife [FG_MidwivesPractitioners 1, 2, 3]. The heavy workload in terms of carrying out a large number of deliveries was highlighted. One midwife said: "We perform an average of 40 deliveries in public maternity wards during a 12-hour night shift" [FG_MidwivesPractitioners2]. The "ratio of women to midwife being too high" was a common refrain of many informants. Midwives described themselves as "working on the maternity wards like machines" [FG_MidwivesPractitioners1]. The heavy workload was leading to "job dissatisfaction and negative impacts on midwives' mental health and quality of care" [FG_MidwivesPractitioners3].

Midwives' pay scale was reported as being incommensurate to their workload leading to frustration, particularly in light of the responsibilities they assume. Moreover, no incentive system exists (extra payment for working night shifts or extra hours). Particular concerns relating to working and living conditions in rural areas were raised. These conditions were described as being unsafe and very problematic for assisting women in a humane way according to a competency-based approach. Inadequate provision for living in remote areas - such as safe housing, electricity, and access to communication means (Internet) - was of major concern:

$[\ldots$.$] in the rural areas, this is the big problem, so for mid-$ wives, it's about the living conditions that are devastating, it's even going to create an impediment to this program, if you give a midwife a small house without enough electricity, without water for an entire year, [...], in your opinion is she going to perform well or apply her new competencies with no electricity? [AcademicDirector1]

All these problems were reported as having some negative influence on midwives. One academic director said: "such poor conditions influence midwives' performance and their willingness and capabilities to adapt to change" [AcademicDirector2]. Many participants raised the problem of professional and social isolation due to the remoteness of some villages. According to some interviewees, "even if the CBE program aims to develop the skills of the midwife, those conditions are not favorable for practicing new midwifery skills" [NurseManager2]. Rotation of midwives occurring 3 years after their assignment to rural areas was stated as a barrier to any midwifery intervention given the major impact on their motivation to apply new skills [AcademicDirector1]. Failure to improve working and living conditions would impede the successful reinforcement of her role [MedicalDirector1].

\section{Readiness for implementation - available resources: Inadaptability of human/material resources and training on the requirements of midwifery practice}

Global short-health care staffing in Morocco and in rural regions and unequal distribution of the midwifery workforce between urban and rural areas were among the barriers stated as hindering the intervention's success. Participants stated that "under such conditions, the CBE program cannot reach its goal and midwives cannot provide women-centered care" [FO_TTT_N6]. The infrastructure for providing quality health care services was seen as inadequate to practice safely and to provide holistic care in some rural birthing homes. It was stated that "lack of oxygen, unequipped ambulances and lack of medical equipment, will hinder our ability to work according to the new competency-based approach" [FO_TTT_N7]. Many midwives commented on the difficulty of providing humanistic care, of applying the competencies learned in understaffed environments [FG_MidwiferyEducators3]. Also, access to obstetricians and anesthetists in rural birthing home areas seems very difficult.

As for postgraduation learning opportunities for midwives, they seem not to be supported through the educational budget [NurseManager1]. Midwives' education has been described as inappropriate for providing care due to the lack of responsiveness of the midwifery training system to the development of scientific knowledge. It was mentioned that: 
The objective of improving the quality of health services through strengthening midwives' role will remain out of reach as long as prior attention is not given to issues pertaining to human, material resources. [NurseManager2]

Failure to address these barriers through activities such as increasing and allocating adequate resources equitably for midwifery practice, in synergy with the CBE program, could seriously impair the achievement of the outcomes according to many interviewees [FG_MedicalAdministrativeOfficers2; FG_MidwivesPractitioners1].

\section{Networks and communications: inadequate} communication and poor interdisciplinary collaboration Poor interprofessional collaboration between obstetricians and midwives was stated as a crucial adverse factor in achieving desired outcomes. Obstetricians and anesthetists' mistrust and lack of respect for midwives were issues posing major barriers that need to be overcome in order to provide women-centered care. Many midwives were concerned with the lack of trust in midwifery practice with regards to the future collaboration needed for practicing according to the competency-based approach [FG_MidwivesPractitioners2]. Physicians' lack of professional trust in midwives' decision making was highlighted, for instance doubting their clinical judgments and their decisions [FG_MidwivesPractitioners1]. Shared decision making was not carried out between the team members, and physicians' decisions were stated as "should always stand" in public hospitals [FG_MidwivesPractitioners1]. Midwives talked about providing care for women alone in the absence of obstetricians who only managed emergency cases. Midwives felt undermined by anesthetists who refused to communicate with them even in emergency cases. They believed that:

Their relationship with anesthetists and physicians as a dominant/dominated relationship type [...] might have an impact on the success of the intervention, on strengthening midwives' role. [FG_MidwiferyEducators4]

Unanimously, the need for support, for respect, and for sharing decision making was emphasized as essential to successfully strengthen the midwifery profession.

\section{Actors}

Role characteristics: Midwife's role misunderstood and misused in the professional field

The lack of a well-defined scope of practice for midwives and a formalized job description, perceived as a major barrier, was linked to the outdated legal framework in Morocco. There appeared to be a consensus amongst the participants that unclear role boundaries had many consequences, including blurring the roles of obstetricians and midwives, their scopes of practice overlapping, and subsequently midwives sometimes doing activities falling within the scope of medical practice. One potential area of conflict mentioned regarding the use of a vacuum extractor in an emergency situation in birthing homes led to fear of litigation [AdministrativeNurseManager1]. Lack of clarity of the role among midwives themselves and among the medical and nursing staff led to an excessive involvement of midwives in nonmidwifery activities in the clinical settings. One midwife stated: "Professional boundaries of midwives are not clear, they can function as a physician, [...], dental assistant, even a cleaning person" [FG_MidwivesPractitioners2]. Concerns regarding the lack of prescribing rights (eg, related to antibiotics) in rural areas were described as hindering their future ability to provide emergency obstetric care [FG_MedicalAdministrativeOfficers5]. In summary, as the action plan's objective suggesting to work on the midwife's statute in Morocco was not fulfilled, almost all midwives, medical administrative officers, and nurses predicted the failure to achieve the CBE program's objective to strengthen the midwife's role.

\section{Discussion}

Data on the contextual factors that interact with the action plan as it has been implemented and that might prevent positive outcomes from being produced belong to the sociocultural and professional systems, which need to be addressed in parallel to the educational system, as predicted by the Hatem-Asmar's framework. ${ }^{13}$

With regards to the sociocultural system, data analysis has shown that the lack of alignment of the current legal framework and regulations governing midwifery practice in Morocco with the forthcoming competency-based program might hamper achievement of the intended outcomes. Old legislation not based on a distinct scope of professional practice was the cause for barriers related to midwifery practice such as lack of job description clarity, and a perceived lack of recognition of the midwife's role among the midwives themselves and other health professionals. Failure to provide an enabling legislative and regulatory framework impedes midwives from positively exploiting the potential of their role; such activities would most likely help to define the standards of midwifery practice and draw professional boundaries to prevent confusion over the scope of practice. ${ }^{23}$ 
Moreover, poor image and lack of recognition of the midwifery profession among the community, reported as a potential barrier to achieving the full role and providing quality health services, were also raised in the literature. For example, Brodie ${ }^{24}$ stated that an under-recognized midwifery profession has serious implications for sociocultural quality, ${ }^{25}$ thus affecting demands being made by consumers. We found that lack of media support is a concern that needs to be addressed by health authorities. Indeed, strategies for raising awareness of the midwife's role (eg, information on websites) had been recommended in previous studies to support midwifery and enable them to fulfill their role. ${ }^{26}$

Our findings also illustrate that midwives operate within a constrained professional system, inconsistent with a competency based approach, which might place high restrictions on fulfilling the role according to the woman-centered approach and on using competencies to meet women's social, emotional, cultural, and physical needs. Midwives face many problems (eg, poor working conditions, critical staff shortages, lack of equipment to provide care), which are attributable to the poor management of human resources at the MOH's level. The need to address these barriers has been emphasized as they affect the midwives' motivation and their professional performance., ${ }^{3,27}$ Our findings with regard to the resource-constrained work environment and difficult teamwork relationships are in line with the barriers (paucity of resources, discrimination of midwives by physicians, and lack of teamwork in the health facilities), challenging the success of an innovative midwifery education program in Afghanistan in terms of strengthening the midwives competencies, providing quality health care and averting maternal deaths. ${ }^{28}$ Investing in human resources and changing the constraining environment (such as inadequate physical structures of labor and lack of teamwork between physicians and midwives) were also recommended by $\mathrm{Narchi}^{29}$ in Brazil to enable midwives to put into practice essential competencies and to provide midwife-led care.

It is noteworthy that the results of this study reflect the situation that was prevailing during the diagnostic phase and that the recommendations suggested by key stakeholders are in agreement with the activities recommended in the initial design of the action plan and that have not been adopted by the $\mathrm{MOH}$. We recall that the initial design was based on the barriers found and the recommendations of the stakeholders interviewed during the diagnostic phase. This offers insights into the consensual views obtained from different stakeholders at different phases (before and during implementation) regarding how to strengthen midwifery. This also implies that the barriers reported in the present study can be converted into activities and can be used to build once again the same intervention, confirming thus the relevance of the initial one.

Our findings revealed that implementing educational activities without considering the activities designed to target the sociocultural and professional systems in which the midwife operates might pose a threat to providing a competent midwifery workforce able to contribute to the provision of quality maternity services. Fostering an environment that is conducive to change by addressing the vital areas of a sustainable midwifery workforce (eg, legislation and regulation, professional and social recognition, practice environment, management of human resources), in addition to educational issues, has been advocated for by many international reports and many studies across the world. In a recent publication of the Lancet series ${ }^{30}$ and toolkits on midwifery by the $\mathrm{WHO},{ }^{23}$ key domains were put forward for national investment in midwives, to strengthen their role as essential providers of skilled care and to maximize their contribution to health: updating educational programs according to the ICM essential competencies to meet community needs, establishing a supportive legislative and regulatory framework for midwifery, and establishing enabling work environments and adequate midwifery workforce management. Carrying out such changes would enable midwives to practice to the full extent of their competencies, which is essential for quality practice and improved standards of care.

Our results are consistent with other research conducted in different countries (eg, the Arab world, Australia, and other countries), recommending widespread changes to the system to align midwifery with international standards in order to contribute effectively to the provision of maternity services. Once again, areas that warrant attention are promoting the recognition of midwifery in society, legislative, and regulatory activities, reforming midwifery education, establishing and funding midwifery-led models of care, and creating a positive working environment. ${ }^{24,31-35}$

In summary, implementing a single intervention of "a global midwifery action plan" seems to be less effective than delivering all the components of the plan according to empirically derived knowledge from the present research and from others conducted in different contexts. Improving midwifery has been consensually conceived within a larger framework depending on the needs of the individual countries aiming to strengthen the midwifery role. Indeed, a fragmented view of change taking place in an educational system without considering the other two systems represents a partially focused view on a complex 
problem, and is only part of what is required for building a competent midwifery workforce. Thus, our results support the conceptual underpinnings regarding how to change a health professional's role that stress the need to address the three systems in which a role evolves and confirm the relevance of the action plan.

Our results emphasize the importance for policymakers to pay attention to the root causes of the problem that, if unaddressed, will mean that efforts to strengthen midwifery will fail. Top-down approaches without an adequate participation of stakeholders concerned by the problem have been described as insufficient because such approaches neglect the integration of the change initiative by the front-line actors. ${ }^{36}$ The participatory approach is one of the most appropriate approaches to redesigning work methods and allows members to play an active role, fostering thus a greater commitment to change. ${ }^{36,37}$ Dussault and Dubois ${ }^{25}$ argued that any process of development and implementation of workforce interventions must adjust to the priorities of the front-line health care providers and consider their full participation in the process.

Our results provide guidance for decision makers on many vital issues that must be addressed concurrently within the system as a whole:

- In the professional system: ensuring effective interprofessional collaboration and establishing a well-functioning team, improving working conditions, mobilizing the midwifery professional association, and reforming the midwifery profile and scope of practice.

- In the sociocultural system: social marketing activities for raising community awareness of the midwifery services and enhancing social acceptability of the profession, reforming the law, and reviewing the management of resources in the Moroccan system.

\section{Strengths and limitations of the study}

This study has several strengths such as the use of an innovative evaluation framework to study the change in the health professional field, and the collection of various views from different systems regarding the factors that might affect outcomes. However, some limitations should be mentioned. The CFIR used as the analytical lens has proved to be very useful for analyzing contextual influences on the implementation process, as had been reported in a previous paper. However, it applies poorly to examining the anticipated barriers for reaching outcomes. Our findings question the CFIR's usefulness for organizing data related to outcomes despite that it has been advanced as a framework that guides implementation and outcome evaluations. Much work is needed to enrich constructs and enable the understanding of contextual influences on reaching outcomes. Furthermore, generalizability may be limited. Findings do not reflect the perspectives of all obstetric health care settings, the Moroccan community as a whole and reproductive health departments affiliated to the $\mathrm{MOH}$ in all regions of Morocco, regarding the potential barriers to reaching outcomes. On the other hand, we were able to gain a deeper understanding of the Moroccan context, which may help readers to decide to what extent results can be transferable to similar settings.

\section{Conclusion}

Our research provides guidance on what combination of interventions may be more conducive to attaining the objective of providing a qualified midwifery workforce able to improve maternal and neonatal health. This implies that policymakers in Morocco must consider the complex interaction of all these barriers and the context that may act as an effect modifier ${ }^{38}$ and adopt a whole system-strengthening approach to help build a stronger midwifery workforce. Activities recommended to address these barriers, targeting the sociocultural and professional systems, may have great potential to reposition midwifery as a full partner in the maternal health improvement process and enhance the success of the national strategy. Being aware of these barriers could guide future intervention efforts in reconsidering the implementation of all the components of the initial action plan to allow the full use of competent and cost-effective primary health care professional. Further research is needed to improve understanding of the mechanisms for successful workforce change in similar contexts with a high burden of maternal death.

\section{Acknowledgments}

The main author of this study benefited from the financial support (scholarships) granted by the Institut de recherche en santé publique de l'Université de Montréal (IRSPUM), the CHIR-Quebec Training Network in Perinatal Research program, and Professor Hatem to collect the data. The authors wish to thank all participants for their willingness to take part in this study. The authors acknowledge the suggestions of Laura J Damschroder, MPH, with regard to applying the CFIR to present the study.

\section{Author contributions}

All authors contributed toward data analysis, drafting and critically revising the paper and agree to be accountable for all aspects of the work. SAM took the lead role in conducting 
the evaluation, collecting and analyzing the data, and writing the manuscript; $\mathrm{MH}$ supervised the phases of the project, participated in the design of the study, made the initial contacts to have access to the field research, validated the qualitative analysis, the methodology and the results, and made several critical revisions of the manuscript. NL validated the analysis and participated in the critical revision of the manuscript.

\section{Disclosure}

The authors report no conflicts of interest in this work.

\section{References}

1. Renfrew MJ, McFadden A, Bastos MH, et al. Midwifery and quality care: findings from a new evidence-informed framework for maternal and newborn care. Lancet. 2014;384(9948):1129-1145.

2. United Nations Population Fund. A Global Call to Action: Strengthen Midwifery to Save Lives and Promote Health of Women and Newborns. United Nations Population Fund; 2010. Available from: http://www. internationalmidwives.org/assets/uploads/documents/CALLtoActionENGJune42010.pdf. Accessed March 9, 2015.

3. United Nations Population Fund. The State of The World's Midwifery Report 2011: Delivering Health, Saving Lives. United Nations Population Fund; 2011. Available from: http://www.unfpa.org/sites/default/ files/pub-pdf/en_SOWMR_Full.pdf. Accessed February 12, 2015.

4. World Health Organization. Strengthening Midwifery Toolkit: Module 1-Strenghtening Midwifery: A Background Paper. Geneva: World Health Organization; 2011. Available from: http://whqlibdoc.who.int/ publications/2011/9789241501965_module1_eng.pdf?ua=1. Accessed March 9, 2015.

5. Champagne F, Brousselle A, Hartz Z, Contandriopoulos AP, Denis JL. L'analyse de l'implantation [Implementation analysis]. In: Brousselle A, Champagne F, Contandriopoulos AP, Hartz Z, editors. L'évaluation. concepts et méthodes [Evaluation: Concepts and Methods]. Montréal: Les Presses de l'Université de Montréal; 2011:238-273. French.

6. Stetler CB, Legro MW, Wallace CM, et al. The role of formative evaluation in implementation research and the QUERI experience. J Gen Intern Med. 2006;21(Suppl 2):S1-S8.

7. Champagne F, Brousselle A, Hartz Z, Contandriopoulos AP. Modéliser les interventions [Modeling the interventions]. In: Brousselle A, Champagne F, Contandriopoulos AP, Hartz Z, editors. L'évaluation: concepts et méthodes [Evaluation: Concepts and Methods]. Montréal: Les Presses de l'Université de Montréal; 2011:71-84. French.

8. Hoddinott P, Britten J, Pill R. Why do interventions work in some places and not others: a breastfeeding support group trial. Soc Sci Med. 2010; 70(5):769-778.

9. Lipsey WM, Cordray SD. Evaluation methods for social intervention. Annu Rev Psychol. 2000;51:345-375.

10. Johnson CA, Cen S, Gallaher P, et al. Why smoking prevention programs sometimes fail. Does effectiveness depend on sociocultural context and individual characteristics? Cancer Epidemiol Biomarkers Prev. 2007;16(6):1043-1049.

11. Royaume du Maroc Ministère de la Santé. Plan d'action pour accélérer la réduction de la Mortalité Maternelle et Infantile: Période 2008-2012 [An Action Plan for Accelerating the Reduction of Maternal and Infant Mortality: Period 2008-2012]. Royaume du Maroc: Ministère de la Santé; 2008. French.

12. Abou-Malham S. Analyse de l'implantation d'un plan d'action pour le renforcement du rôle professionnel de la sage-femme dans le Royaume du Maroc [Implementation Analysis of an action plan to strengthen the midwifery professional role in Morocco] [dissertation]. Accra: University of Montréal; 2014. French.
13. Hatem-Asmar M, Fraser W, Blais R. Trois paradigmes pour développer un programme de formation des professionnels de la santé: le cas de la formation des sages-femmes au Québec [Three paradigms for developing a training program for health professionals: the case of midwifery training in Québec]. Ruptures, revue transdisciplinaire en santé. 2002;9(1):86-102. French.

14. Abou-Malham S, Hatem M, Leduc N. Understanding the implementation of a complex intervention aiming to change a health professional role: a conceptual framework for implementation evaluation. Open $J$ Philos. 2013;3:491-501.

15. Damschroder LJ, Aron DC, Keith RE, Kirsh SR, Alexander JA, Lowery JC. Fostering implementation of health services research findings into practice: a consolidated framework for advancing implementation science. Implement Sci. 2009;4:50.

16. Miles MB, Huberman AM. Qualitative Data Analysis. 2nd ed. Thousand Oaks, CA: Sage Publications; 1994.

17. Yin RK. Case Study Research: Designs and Methods. 4th ed. Thousand Oaks, CA: SAGE Publications; 2009.

18. Patton MQ. Qualitative Research and Evaluation Methods. 3rd ed. Thousand Oaks, CA: Sage Publications; 2002.

19. Thomas DR. A general inductive approach for analyzing qualitative evaluation data. Am J Eval. 2006;27(2):237-246.

20. Durlak J, DuPre E. Implementation matters: a review of research on the influence of implementation on program outcomes and the factors affecting implementation. Am J Community Psychol. 2008;41: 327-350.

21. Lukas CV, Meterko MM, Mohr D, et al. Implementation of a clinical innovation: the case of advanced clinic access in the Department of Veterans Affairs. J Ambul Care Manage. 2008;31(2):94-108.

22. Love A. Implementation evaluation. In: Wholey JS, Hatry HP, Newcomer KE, editors. Handbook of Practical Program Evaluation. 2nd ed. San Francisco: Jossey-Bass; 2004:63-97.

23. World Health Organization. Strengthening Midwifery Toolkit: Module 2 - Legislation and Regulation of Midwifery - Making Safe Motherhood Possible. Geneva: World Health Organization; 2011. Available from: http://whqlibdoc.who.int/publications/2011/9789241501965_ module2_eng.pdf?ua=1. Accessed March 9, 2015.

24. Brodie P. Addressing the barriers to midwifery-Australian midwives speaking out. Aust J Midwifery. 2002;15(3):5-14.

25. Dussault G, Dubois CA. Health, Nutrition and Population (HNP) Discussion Paper: Human Resources For Health Policies: A Critical Component in Health Policies. 2004. Available from: http://siteresources.worldbank.org/HEALTHNUTRITIONANDPOPULATION/ Resources/281627-1095698140167/DussaultDuboisHRHealthPolicies. pdf. Accessed February 8, 2015.

26. Research Power Inc. Implementation of Midwifery In Nova Scotia Prepared for: Nova Scotia Department of Health and Reproductive Care Program of Nova Scotia. 2010. Available from: http://legcat.gov. ns.ca/record=b1062400. Accessed February 14, 2015.

27. Mathauer I, Imhoff I. Health worker motivation in Africa: the role of non-financial incentives and human resource management tools. Hum Resour Health. 2006;4(1):24.

28. United States Agency for International Development Afghanistan. Program Evaluation of the Pre-Service Midwifery Education Program in Afghanistan Final Phase One Report. 2009. Available from: http:// pdf.usaid.gov/pdf_docs/PDACQ112.pdf. Accessed March 12, 2015.

29. Narchi NZ. Exercise of essential competencies for midwifery care by nurses in São Paulo, Brazil. Midwifery. 2011;27(1):23-29.

30. ten Hoope-Bender P, de Bernis L, Campbell J, et al. Improvement of maternal and newborn health through midwifery. Lancet. 2014; 384(9949):1226-1235.

31. Hassan-Bitar S, Narrainen S. 'Shedding light' on the challenges faced by Palestinian maternal health-care providers. Midwifery. 2011; 27(2):154-159.

32. Hauck YL, Bayes SJ, Robertson JM. Addressing the workplace needs of Western Australian midwives: a Delphi Study. Aust Health Rev. 2012;36(2):176-183. 
33. Homer CS, Passant L, Brodie PM, et al. The role of the midwife in Australia: views of women and midwives. Midwifery. 2009;25(6):673-681.

34. Shaban I, Barclay L, Lock L, Homer C. Barriers to developing midwifery as a primary health-care strategy: a Jordanian Study. Midwifery. 2012;28(1):106-111.

35. Kildea S, Larsson M, Govind S. A review of midwifery in Mongolia utilising the Strengthening Midwifery Toolkit. Women Birth. 2012; 25(4):166-173.

36. Zink KJ, Steimle U, Schröder D. Comprehensive change management concepts: development of a participatory approach. Appl Ergon. 2008; 39(4):527-538.
37. Vink P, Imada AS, Zink KJ. Defining stakeholder involvement in participatory design processes. Appl Ergon. 2008;39(4):519-526.

38. Jackson N, Waters E, Guidelines for Systematic Reviews in Health Promotion and Public Health Taskforce. Criteria for the systematic review of health promotion and public health interventions. Health Promot Int. 2005;20(4):367-374.

\section{Publish your work in this journal}

The Journal of Multidisciplinary Healthcare is an international, peerreviewed open-access journal that aims to represent and publish research in healthcare areas delivered by practitioners of different disciplines. This includes studies and reviews conducted by multidisciplinary teams as well as research which evaluates the results or conduct of such teams or healthcare processes in general. The journal covers a wide range of areas and welcomes submissions from practitioners at all levels, from all over the world. The manuscript management system is completely online and includes a very quick and fair peer-review system. Visit http://www.dovepress.com/testimonials.php to read real quotes from published authors.

Submit your manuscript here: http://www.dovepress.com/journal-of-multidisciplinary-healthcare-journal 